\title{
Pengaruh Terapi Though Stopping Terhadap Peningkatan Kualitas Tidur Lanjut Usia di Balai Sosial Lanjut Usia Mandalika NTB
}

\author{
Awan Dramawan ${ }^{1(\mathrm{CA})}$, Muhammad Muttaqin ${ }^{2}$, Ely Mawaddah $^{3}, \mathrm{Cembun}^{4}$ \\ 1(CA)Jurusan Keperawatan, Poltekkes Kemenkes Mataram, Indonesia; awandramawan64@gmail.com \\ (Corresponding Author) \\ 2,3,4 Jurusan Keperawatan, Poltekkes Kemenkes Mataram, Indonesia
}

\begin{abstract}
The need for sleep is a basic need in human survival, especially for the elderly as a population at risk and in dire need of good sleep quality, most of the elderly experience poor sleep quality so that the choice of Thought Stopping therapy in addition to reducing anxiety also has an effect short-term positives such as relaxation, improved sleep quality, reduced mood and negative thoughts. This study aims to provide an overview of improving the sleep quality of the elderly who receive Thought Stopping therapy. This study design is a quasi-experimental pre-posttest with Thought Stopping therapy intervention. The sample was was 30 elderly people who experienced poor sleep quality at BSLU Mandalika NTB and taken using purposive sampling technique. The results of Wilcoxon test showed p-value $=.000$ which means that there is an effect of Thought Stopping therapy on improving the sleep quality of the elderly at BSLU Mandalika NTB. It can be concluded that Thought Stopping therapy is effective in improving sleep quality. This study results suggest the application of Thought Stopping therapy as an intervention to improve the sleep quality of the elderly.
\end{abstract}

Keywords: Thought Stopping therapy; sleep quality

\begin{abstract}
ABSTRAK
kebutuhan tidur merupakan merupakan kebutuhan yang mendasar dalam kelansungan hidup manusia, terutama untuk lanjut usia sebagai populasi yang beresiko dan sangat membutuhkan kualitas tidur baik, sebagian besar lanjut usia mengalami kualitas tidur yang buruk sehingga pemilihan terapi Thought Stopping selain mengurangi ansietas juga memberikan efek positif jangka pendek seperti relaksasi, meningkatkan kualitas tidur, suasana hati dan pemikiran negatif berkurang. Penelitian ini bertujuan memberikan gambaran peningkatan kualitas tidur lansia yang mendapatkan terapi Thought Stopping.Metode Penelitian: Desain penelitian ini adalah Quasi experimental pre-post test dengan intervensi terapi thought stopping. Populasi penelitian ini sebanyak 84 dan Besar sampel penelitian dengan tehnik purposive sampling sebanyak 30 orang lansia yang mengalami kualitas tidur yang buruk di BSLU Mandalika NTB, analisis yang digunakan uji Wilcoxon .Hasil Penelitian: ( p-value ,000 ) yang berarti terdapat pengaruh terapi Thought Stopping terhadap peningkatan kualitas tidur lansia di BSLU Mandalika NTB. Kesimpulan: Dari hasil penelitian ini dapat dikatakan bahwa terapi Thought Stopping efektif dalam meningkatkan kualitas tidur.Saran: Di sarankan hasil penelitian ini dapat diterapkan dan diajarkan kepada lansia mengenai terapi Thought Stopping agar bisa menambah wawasan dan pengalaman kedalam praktik nyata sebagai intervensi dalam meningkatkan kualitas tidur lansia.
\end{abstract}

Kata kunci: terapi Thought Stopping; Kualitas tidur 


\section{PENDAHULUAN}

Kebutuhan yang paling dasar, kuat, dan jelas dalam mempertahankan hidup adalah kebutuhan fisiologis yang dimana terdapat salah satu di dalamnya kebutuhan istirahat tidur. Perubahan fisiologis yang terjadi pada lansia diantaranya menurunnya fungsi: sel, sistem kardiovaskuler, sistem pernafasan, sistem persyarafan, integumen dan muskuloskeletal. Oleh sebab itu setiap orang sangat membutuhkan istirahat dan tidur yang cukup untuk organ di atas berfungsi secara optimal (Haryati 2013) terutama untuk lanjut usia harus terpenuhi kebutuhan istirahat tidurnya sehingga mendapatkan kualitas tidur yang baik.

Apabila Kualitas tidur pada lanjut usia terganggu maka akan berdampak buruk terhadap kesehatan karena dapat menyebabkan kerentanan terhadap penyakit, stres, gangguan mood, kurang fresh, menurunnya kemampuan berkonsentrasi, dan menurunnya kemampuan membuat keputusan (Potter \& Perry, 2009). Jumlah lanjut usia di kawasan Asia Tenggara populasi Lansia sebesar 8\% atau sekitar 142 juta jiwa. Pada tahun 2050 diperkirakan populasi lansia meningkat 3 kali lipat dari tahun ini (World Health Organization. 2014). Sedangkan Di Indonesia sendiri pada tahun 2021 diperkirakan jumlah lansia sekitar 80.000.000 (Kemenkes RI, 2013). Menurut United Nations (2015) Indonesia memiliki jumlah lansia urutan ke-4 terbesar didunia, setelah negara China, India dan Amerika. Menurut Data Badan Pusat Statistik (2014) menyebutkan bahwa jumlah lansia di Indonesia mencapai 20,04 juta orang atau sekitar 8,05\% dari seluruh penduduk Indonesia. Sedangkan Di NTB sendiri jumlah lansia mencapai 5.070.385 juta jiwa atau 8,48 \% dari seluruh penduduk Provinsi Nusa Tenggara Barat (profil lansia provinsi nusa tenggara barat 2019., 1387).

Meningkatnya jumlah lansia tersebut mengakibatkan munculnya beberapa fenomena seperti perubahan struktural dan fisiologis salah satunya adalah kesulitan untuk tidur atau insomnia (Sitralita, 2010), Menurut data WHO, lansia yang mengalami gangguan tidur per tahun meningkat jumlahnya. Prevalensi gangguan tidur pada lansia cukup tinggi yaitu sekitar 67\% pada tahun 2010 (World Health Organization dalam Yunita, 2012). Sedangkan di Indonesia sendiri khususnya daerah Jawa Timur kejadian insomnia pada lansia pada tahun 2009 mencapai sekitar $10 \%$ dari seluruh jumlah lansia dijawa timur dan 3\% diantaranya mengalami gangguan yang serius (Tommy Kurniawan,2012).

Hal di atas terjadi dikarenakan banyak lansia yang mengeluh hanya dapat tidur tidak lebih dari lima jam sehari dengan terbangun lebih awal dari pukul 05.00 pagi dan sering terbangun di waktu malam hari dan tidak bisa untuk kembali teridur (Nugroho, 2000). Pada kondisi tersebut. Kualitas Tidur yang baik suatu hal yang sangat diperlukan untuk menjaga keseimbangan mental, fisiologi, emosional, dan kesehatan (Aspiani, 2014). Upaya yang dapat dilakukan dalam menangani masalah tidur gangguan tidur adalah dengan pemberian obat tidur padahal pemberian obat tidur dalam jangka waktu yang lama dapat menimbulkan efek samping, kecanduan, dan bila overdosis dapat membahayakan pemakainya (Nugroho, 2008).

Berdasarkan efek buruk dari penggunaan obat tidur, terlebih pada lansia yang dimana proses metabolisme berbeda dengan orang dewasa muda. Maka terapi non farmakologis merupakan pilihan tepat . berikut beberapa terapi non farmakologi yang bisa digunakan dalam menangani masalah kualitas tidur lansia seperti : terapi meditasi, terapi musik, terapi relaksaasi nafas dalam, aroma terapi membaca, latihan fisik, terapi relaksasi otot progresif dan lain-lain (Maryamdkk, 2010). Bertitik tolak dari penomena yang 
ada, sebagai dasar masyarakat tidak perlu lagi membeli obat yang mahal untuk mengatasi gangguan tidur sehingga masyarakat dapat hidup jauh lebih hemat dan murah dari ekonominya dengan harapan masyarakat melakukan terapi Thought Stopping yang tidak memiliki efek samping.

Teknik Thought Stopping merupakan salah satu teknik dalam pendekatan konseling kognitif behavioral yang dapat digunakan untuk mengubah pikiran negatif seseorang menjadi pikiran yang positif. Pikiran yang positif dapat memunculkan tingkah laku positif, dengan cara menekan atau menghilangkan kesadaran-kesadaran negatif tersebut dan memberikan instruksi kepada diri sendiri (swaperintah) untuk menghentikan alur pikiran negatif melalui penghadiran rangsangan atau stimulus yang mengagetkan. Mengapa diperlukan stimulus yang mengagetkan, didasarkan pada pandangan bahwa pikiran itu ketika beroperasi akan berjalan seperti aliran sungai. Aliran pikiran ini dapat dibuyarkan atau dihambat jalannya sehingga terputus melalui cara pemblokiran secara sederhana.

Thought Stopping (Berhenti berfikir) sering kali juga untuk klien yang terlalu terpaku dengan kejadian-kejadian masa lalu yang tidak dapat diubah, klien yang menyesali kejadian-kejadian yang tidak mungkin terjadi, klien yang terikat oleh fikiran negatif yang selalu berulang-ulang dan sangat tidak produktif atau kegelisahan yang berulang-ulang atau gambaran-gambaran yang selalu menyalahkan diri sendiri sehingga membuat klien kesusahan dalam memulai istirahat tidur yang mengakibatkan kualitas tidurnya sangat buruk. Berdasarkan hasil observasi lingkungan dan wawancara lansia Di Balai Sosial Lanjut Usia (BSLU) Mandalika NTB Tahun 2021, menyatakan bahwa dari 84 responden lansia yang tinggal di panti, $30(35,7 \%)$ mengalami gangguan tidur yang menyebabkan kualitas tidurnya buruk. Gangguan tidur pada lansia tersebut disebabkan oleh berbagai faktor seperti: status kesehatan, lingkungan, stres psikologis, diet, gaya hidup, obat-obatan (Prayitno, 2002). Berdasarkan hasil tersebut gangguan tidur menjadi keluhan terbanyak di Balai Sosial Lanjut Usia Mandalika NTB.

\section{METODE}

Dalam Penelitian ini menggunakan desain Quasi Experiment. Rancangan ini menggunakan dua kelompok sampel yang diwawancara sebanyak dua kali, yaitu wawancara sebelum eksperimen (pretest) dan wawancara sesudah eksperimen (posttest). Populasi dalam penelitian ini adalah semua lanjut usia yang berada di Balai Sosial Lanjut Usia (BSLU) Mandalika NTB berjumlah 84 orang lansia. Penentuan sampel dilakukan dengan menggunakan purposive sampling dengan kriteria inklusi dan eksklusi sebagai berikut: Kriteria inklusi: lansia di BSLU Mandalika berusia >50-120 tahun dan mengalami gangguan tidur dan tidak memiliki gangguan jiwa. Kriteria ekslusi: lansia yagn dalam perawatan intensif, tidak berada di tempat saat penelitian dan lansia post stroke. Jumlah sampel yang diambil sebanyak 30 orang.

Variabel penelitian adalah terapi Thought Stopping (independen) dan kualitas tidur lansia (dependen). Pretes dan posttes dilakukan dengan menggunakan kuesioner yang telah ditetapkan. Data yang dikumpulkan meliputi data primer yaitu kualitas tidur lansia sebelum dan sesudah dilakukan terapi Thought Stopping, dan data sekunder meliputi data usia dan jenis kelamin responden. Analisa data menggunakan analisis univariat untuk data responden seperti umur, jenis kelamin dan data kualitas tidur lansia. Analisis data bivariat dilakukan menggunakan uji Wilcoxon untuk menguji perbedaan kualitas tidur lansia sebelum dan sesudah dilakukan terapi Thought Stopping. 


\section{HASIL}

Hasil penelitian berupa data sekunder (usia dan jenis kelamin) dan data primer dapat dilihat pada tabel-tabel berikut ini:

Tabel 1. Distribusi Responden Berdasarkan Usia dan Jenis Kelamin

\begin{tabular}{cccc}
\hline No & Karakteristik Responden & Frekuensi & Persentase $(\%)$ \\
\hline Usia & Responden & & \\
1 & $>50$ tahun & 6 & 19,0 \\
2 & $60-74$ tahun & 8 & 27,0 \\
3 & $75-90$ tahun & 11 & 37,0 \\
4 & $>90$ tahun & 5 & 17,0 \\
Jenis Kelamin & Laki-laki & & \\
1 & Perempuan & 13 & 43,0 \\
2
\end{tabular}

Berdasarkan tabel diatas diketahui bahwa sebagian besar responden berjenis kelamin perempuan $(57 \%)$ dan berusia 75-90 tahun (37\%). Untuk data kualitas tidur lansia dapat dilihat pada tabel 2 dibawah ini.

Tabel 2. Kualitas Tidur Lansia Sebelum dan Sesudah pemberian Thought Stopping

\begin{tabular}{|c|c|c|c|}
\hline No & Skor kualitas tidur lansia & Frekuensi & Persentase $(\%)$ \\
\hline \multicolumn{4}{|c|}{ Sebelum pemberian Thought Stopping } \\
\hline 1 & Kualitas tidur buruk $>5$ & 30 & 100,0 \\
\hline 2 & Kualitas tidur baik $<5$ & 0 & 0,0 \\
\hline \multicolumn{4}{|c|}{ Setelah pemberian Thought Stopping } \\
\hline 1 & Kualitas tidur baik $<5$ & 30 & 100,0 \\
\hline 2 & Kualitas tidur buruk $>5$ & 0 & 0,0 \\
\hline
\end{tabular}

Tabel 2 menunjukkan bahwa seluruh responden mengalami kualitas tidur buruk sebelum dilakukan terapi Thought Stopping dan mengalami kualitas tidur baik setelah dilakukan terapi Thought Stopping.

Tabel 3. Hasil Uji Wilcoxon Terhadap Kualitas Tidur Lansia Sebelum Dan Sesudah Dilakukan Terapi Thought Stopping

\begin{tabular}{|c|c|c|c|c|c|c|}
\hline Variabel & $\mathbf{N}$ & $\begin{array}{c}\text { Nilai } \\
\text { Minimum } \\
\end{array}$ & $\begin{array}{c}\text { Nilai } \\
\text { Maksimum } \\
\end{array}$ & Mean & $\begin{array}{l}\text { Standar } \\
\text { Deviasi }\end{array}$ & $P$ \\
\hline $\begin{array}{l}\text { Kualitas tidur sebelum Terapi } \\
\text { Thought Stopping }\end{array}$ & 30 & 6 & 10 & 7.97 & .999 & \multirow[t]{2}{*}{.000} \\
\hline $\begin{array}{l}\text { Kualitas tidur setelah Terapi } \\
\text { Thought Stopping }\end{array}$ & 30 & 2 & 5 & 3.60 & 1.003 & \\
\hline
\end{tabular}


Tabel 3 menunjukkan bahwa $\mathrm{p}=0.000$ yang berarti ada perbedaan signifikan kualitas tidur lansia seblumd an sesudah diberikan terapi Thought Stopping.

\section{PEMBAHASAN}

\section{Kualitas Tidur Lansia Sebelum Diberikan Terapi Thought Stopping}

Berdasarkan hasil penelitian yang di lakukan pada 30 responden menunjukan bahwa sebelum diberikan intervensi terapi Thought Stopping, distribusi responden dengan kualitas buruk sebanyak (30 orang) dengan persentase (100\%). Gangguan tidur pada kelompok lansia cukup tinggi terutama pada lansia yang tinggal di panti, sebagaimana hasil penelitian Khasanah dan Hidayati (2012) yang menyatakan bahwa dari 97 responden lansia yang tinggal di panti 68 (70,1\%) mengalami gangguan tidur yang menyebabkan kualitas tidurnya buruk. Gangguan tidur tersebut disebabkan oleh berbagai faktor seperti: status kesehatan, faktor lingkungan, stress psikologis, diet, gaya hidup, obat-obatan (Asmadi. 2008). Hal tersebut dapat terjadi seiring dengan proses degeneratif yang dialami ditandai dengan kesulitan memulai tidur, sering terbangun pada malam hari dan kesulitan untuk kembali tidur kembali dan bangun pada dini hari.

Hal serupa dikemukan oleh (Potter \& Perry, 2009) bahwa lansia sering kali kesulitan untuk mencapai tidur yang dalam pada tahap 3 dan 4 NREM, dikarenakan berkurangnya volume otak, penurunan fungsi neurotransmiter dan konduksi saraf perifer pada lansia menyebabkan terjadinya penurunan impuls listrik dari dan kesusunan saraf pusat. Penurunan fungsi neurotransmiter menyebabkan menurunnya produksi hormon melatonin yang berpengaruh terhadap perubahan irama sirkadian, sehingga menyebabkan perubahan siklus tidur lansia pada tahap NREM III dan IV. Lansia akan mengalami penurunan tahap III dan IV dari waktu tidur NREM, bahkan sampai hampir tidak memiliki tahap IV atau tidur dalam (Stanley, 2006; Stockslager, 2003). Hal yang serupa dikemukakan oleh Vitiello (2009) bahwa seiring dengan proses penuaan tidur pada lansia menjadi lebih terfragmentasi dan lebih banyak menghabiskan waktu tidur pada tahap tidur ringan yaitu tahap I dan II tidur NREM.

Hal di atas serupa juga dengan pernyatan responden dari hasil 7 komponen kuesioner sebelum diberikan terapi Thought Stopping yaitu 30 orang lansia yang menjadi responden mengatakan kualitas tidurnya secara obyektif cukup buruk, dengan durasi tidurnya yaitu 5-6 jam/hari, tidak dapat memulai tidur dalam waktu 30 menit awal dan sering mengantuk pada siang hari namun hanya beberapa dari responden yang menggunakan obat tidur sebagai solusinya dengan riwayat penggunaan terakhir 2 bulan yang lalu namun melihat efek samping yang di timbulkan yaitu dapat membuat ketergantungan, oleh karena itu sangat di sarankan untuk responden menggunakan obat non farmakologis yaitu terapi Thought Stopping yang dapat mengurangi ansietas, juga memberikan efek positif jangka pendek seperti relaksasi, meningkatkan kualitas tidur, suasana hati dan pemikiran negatif berkurang dengan prinsip keterampilan memberikan instruksi kepada diri sendiri untuk menghentikan alur pikiran negatif melalui penghadiran rangsangan atau stimulus yang mengagetkan. Permuculan pikiran negative dapat diblokir atau dikacaukan alirannya dengan instruksi "TIDAK atau STOP" 


\section{Kualitas Tidur Lansia Setelah Diberikan Terapi Thought Stopping}

Berdasarkan hasil penelitian yang di lakukan pada 30 responden, menunjukkan hasil bahwa setelah diberikan intervensi terapi Thought Stopping kualitas tidur lansia meningkat menjadi baik yaitu sebanyak (30 orang ) dengan persentase (100\%). Kualitas tidur dinyatakan meningkat baik ketika seseorang tidak menunjukan tanda- tanda kekurangan tidur dan tidak mengalami masalah dalam tidurnya. Tanda- tanda kekurangan tidur secara fisik antara lain terdapat area gelap di sekitar mata, bengkak dikelopak mata, kunjungtiva dan mata terlihat cekung, kantuk yang berlebihan, tidak mampu berkonsentrasi, dan menunjukan keletihan. Tanda-tanda psikologis terdiri dari menarik diri, apatis, malas, daya ingat menurun, bingung, halusinasi, ilusi penglihatan dan penurunan kemampuan mengambil keputusan. Beberapa faktor yang mempengaruhi kuantitas dan kualitas tidur yaitu, faktor fisiologis, faktor psikologis, lingkungan dan gaya hidup. Dari faktor fisiologis berdampak dengan penurunan aktivitas sehari - hari, rasa lemah, lelah, daya tahan tubuh menurun, dan ketidak stabilan tanda tanda vital, sedangkan dari faktor psikologis berdampak depresi, cemas, dan sulit untuk konsentrasi (Potter dan Perry. 2005).

Hal di atas serupa dengan pernyatan responden dari hasil 7 komponen kuesioner setelah diberikan terapi Thought Stopping yaitu 30 orang lansia yang menjadi responden mengatakan kualitas tidurnya secara obyektif cukup baik, dengan durasi tidurnya yaitu $>7$ jam/hari, ini disebabkan terapi Thought Stopping sangat mudah di aplikasikan diamanapun dan kapanpun yang dapat mengurangi ansietas, ansietas juga memberikan efek positif jangka pendek seperti relaksasi, meningkatkan kualitas tidur, suasana hati dan pemikiran negatif berkurang. Namun dalam pelaksanaannya di harapkan lansia untuk tetap berfokus dan berkonsentrasi selama kegiatan berlangsung agar mendapatkan efek yang maksimal pada terapi ini, namun pada penelitian ini para responden lansia tetap dalam keadaan berfokus dan berkonsentrasi ini di karenakan intervensi di berikan kepada lansia dibetrikan dengan cara kunjungan ke setiap wisma untuk menjaga pencegahan penularan covid-19.

\section{Analisa Pengaruh Terapi Thought Stopping Terhadap Kualitas Tidur Lansia.}

Uji statistic non parametric Wilcoxon Sign Rank Test dengan analisis $\alpha=0,05$ diperoleh hasil $p$ 0.00 dan $\alpha=0,05$ yang berarti ada pengaruh terapi Thought Stopping terhadap kualitas tidur lansia di balai Lanjut Usia Mandalika NTB. Perubahan pola tidur lansia berhubungan dengan perubahan sistem neurologis dimana terjadi penurunan jumlah dan ukuran neuron pada sistem saraf pusat. Hal ini mengakibatkan fungsi neurotransmiter pada sistem neurologi menurun (Muhtar \& Aniharyati, 2019). Berkuranganya neurotransmiter tersebut berdampak juga pada penurunan produksi hormon melatonin yang mempengarui tidur lansia. Dengan perubahan yang terjadi pada pola tidur lansia tersebut menyebabkan lansia mengalami gangguan tidur yang akan berpengaruh pada kesehatan fisik, sosial dan psikologisnya lansia, sehingga menyebabkan berbagai permasalahan seperti perasaan bingung, curiga, dan terjadinya perubahan atau gangguan suasana hati, gangguan performa motorik, memori dan keseimbangan (Vitiello, 2009).

Seseorang dengan gangguan psikologis dan fisiologis ini akan mengalami beberapa gejala. Seperti merasa gugup, takut, tegang, panik, detak jantung yang cepat, hiperventilasi, gemetar, lemah, lesu, pusing, mual, susah berkonsentrasi, hingga kesulitan tidur atau insomnia oleh sebab itu Thought Stopping 
sebagai intervensi dengan pertimbangan bahwa Thought Stopping selain memberikan pengaruh secara fisik terhadap kualitas tidur responden, Thought Stopping juga dapat mempengaruhi psikologis responden. Dengan pengaruh tersebut tehnik Thought Stopping dapat memberikan pengaruh yang positif terhadap peningkatan kualitas tidur seseorang. Prinsip healing touch pada Thought Stopping lebih menunjukan prilaku caring yang dapat memberikan ketenangan, kenyamanan, rasa dicintai dan diperhatikan bagi klien seperti halnya yang di kemukakan oleh (Isra, Djumaira 2021) dalam jurnalnya Terapi Thought Stopping selain mengurangi ansietas juga memberikan efek positif jangka pendek seperti relaksasi, meningkatkan kualitas tidur, suasana hati dan pemikiran negatif berkurang.

\section{KESIMPULAN}

Berdasarkan hasil penelitian dapat disimpulkan bahwa ada perbedaan signifikan dari kualitas tidur lansia sebelum dan sesudah diberikan terapi thought stopping. Hal ini menunjukkan bahwa terapi thought stopping dapat meningkatkan kualitas tidur lansia. Terapi ini dapat menurunkan ansietes dan perasaan rileks sehingga membuat suasana hati responden menjadi lebih baik dan dapat beristirahat/tidur dengan nyaman sehingga mendapatkan kualitas tidur yang lebih baik. Hasil penelitian ini menunjukkan bahwa terapi thought stopping dapat diaplikasikan sebagai salah satu intervensi keperawatan untuk meningkatkan kualitas tidur lansia.

\section{DAFTAR PUSTAKA}

Anonim, 2004, Mekanisme tidur.buku ajar fudamental keperawatan.jakarta

Asmadi. (2008). Tehnik Prosedural Keperawatan: Konsep dan Aplikasi Kebutuhan Dasar Klien. Jakarta: Salemba.

Aspiani. Reny. (2014). Buku Ajar Asuhan Keperawatan Gerontik Aplikasi NANDA, NIC, dan NOC Jilid 1. Jakarta: Trans Info Media

Azizah, L. 2011. Keperawatan Lanjut Usia. Graha Ilmu: Yogyakarta

Gunawan L, 2001 dalam Wahyuningsih 2007. Gangguan Tidur Buku Ajar Fundamental Keperawatan, Konsep, Proses Dan Praktik Vol 3. Edisi.jakarta.EGC.

Gunawan.(2001). Insomnia. Yogyakarta: Kanisius

Haryati. 2013. Hubungan Antara Kualitas Tidur Dengan Denyut Jantung Dilihat dari Gambaran EKG Pada Pasien Infark Miokard di Ruang ICVCU RSUD DR. Moewardi Surakarta Tahun 2011. Jurnal Kesmadaska, Vol. 4, Juli 2013.

Hidayat. (2008). Pengantar konsep dasar keperawatan (Ed 2). Jakarta: Salemba Medika.https://media.neliti.com/media/publications/188272-ID-none.pdf diakses tgl 15 okt 2021

Iskandar. 2016. Implementasi Teori Hirarki Kebutuhan Abraham Maslow Terhadap Peningkatan Kinerja Pustakawan. Jurnal Ilmu Perpustakaan, Informasi, dan Kearsipan Khizanah Al-Hikmah, Vol. 4 No. 1. ISSN: 2354-9629.

Malakouti, S. K., Foroughan, M., \& Nojomi, M. (2009). Sleep patterns, sleep disturbances and sleepiness in retired Iranian elders 
Maryam, R. Siti, dkk. (2008). Mengenal Usia lanjut dan Perawatannya. Jakarta : Salemba Medika.

Muhtar, \& Aniharyati. (2019). Dukungan Pemenuhan Activity Daily Living (ADL) Pada Lanjut Usia di Balai Sosial Lanjut Usia Meci Angi. Bima Nursing Journal, 1(1), 64-69. https://doi.org/https://doi.org/10.32807/bnj.v1i1.533

Nugroho (2008). Keperawatan Gerontik. Buku Kedokteran EGC: Jakarta.

Nugroho. 2000. Keperawatan Gerontik. Jakarta: EGC.

Polit, D. F. \& Beck, C. T. (2006). Essentials of nursing research: Methods, appraisal, and utilization. (6th Ed). Philadelphia: Lippincott William \& Wilkins.

Potter \& Perry. (2005). Buku Ajar Fundamental Keperawatan; Konsep, Proses dan Praktik Edisi 4 Volume 2. Jakarta: EGC.

Potter dan Perry. 2005. Buku Ajar Fundamental Keperawatan, Konsep, Proses, dan Praktik. Jakarta: EGC.

Potter, P. A., \& Perry, A. G. (2009). Fundamental keperawatan. Buku 3 Edisi 7. Jakarta: Salemba Medika

Prasadja, A. (2009). Ayo bangun dengan bugar karena tidur yang benar. Jakarta: Penerbit Hikmah

Prayitno, A. 2002. Gangguan Pola Tidur pada Kelompok Usia Lanjut dan Penatalaksanaannya. Jurnal Kedokteran Trisakti, Vol. 21 No. 12002.

Stanley, M., \& Gauntlett, B. P. (2006). Buku ajar keperawatan gerontik edisi 2. Jakarta. EGC

Vitiello. 2009. National Sleep Foundation: Aging and Sleep. Melalui

Yulianti, Devi. 2003. Manajenmen Stress. Jakarta: EGC 